\title{
Behaviors of nonlinearities modulating the El Niño events induced by optimal precursory disturbances
}

\author{
Wansuo Duan • Yanshan Yu • \\ Hui Xu $\cdot$ Peng Zhao
}

Received: 15 December 2011/Accepted: 3 October 2012/Published online: 18 October 2012

(C) The Author(s) 2012. This article is published with open access at Springerlink.com

\begin{abstract}
In the present paper, we explore the manner in which nonlinearities modulate El Niño events by investigating the optimal precursory disturbance for El Niño events in the Zebiak-Cane model. The initial anomalies of conditional nonlinear optimal perturbations (CNOPs) and linear singular vectors (LSVs) are investigated. The CNOPs evolve into stronger El Niño events than the LSVs and act as the optimal precursor for El Niño events. By examining the role of nonlinearities in El Niño events induced by CNOPs and LSVs, we determined that, when the initial anomalies of the CNOP and LSV structures are large, the nonlinearities enhance CNOP-El Niño events but suppress LSV-El Niño events. Nonlinearities in the ZebiakCane model arise from nonlinear temperature advection (NTA), sub-surface temperature parameterization (STP), and wind stress anomalies (WSA). Using these types of nonlinearities, we trace the approach of the nonlinearities modulating the CNOP- and LSV-El Niño events. The results demonstrate that nonlinearities that originate from NTA enhance both CNOP-El Niño events and LSV-El Niño events, while nonlinearities originating from STP and WSA suppress these events. For the CNOP-El Niño events, the enhancement effect of NTA is larger than the
\end{abstract}

W. Duan $(\bowtie) \cdot$ H. Xu $\cdot$ P. Zhao

LASG, Institute of Atmospheric Physics, Chinese Academy of Sciences, Beijing 100029, China

e-mail: duanws@lasg.iap.ac.cn

Y. Yu

Institute of Oceanology, Chinese Academy of Sciences,

Qingdao 266071, China

P. Zhao

Graduate University of the Chinese Academy of Science,

Beijing 100049, China suppression effect of STP and WSA, resulting in the combined effect of the nonlinearities in the Zebiak-Cane model being an enhancement of the CNOP-El Niño events. However, for the LSV-El Niño events, the enhancement effect of NTA is smaller than the suppression effect of WSA and STP. Consequently, the combined effect of the nonlinearities in the Zebiak-Cane model suppresses the LSV-El Niño events.

Keywords El Nino $\cdot$ Nonlinearity $\cdot$ Optimal perturbation

\section{Introduction}

The El Niño-Southern Oscillation (ENSO) is a global coupled ocean-atmosphere phenomenon. Numerous models have been developed to simulate and predict ENSO events (Suarez and Schopf 1988; Battisti and Hirst 1989; Wang and Fang 1996; Jin 1997a, b; Wang et al. 1999; Kleeman 1993; Rosati et al. 1997). Although significant achievements have been made in ENSO theories and predictions, forecasting of the ENSO must be further improved (Kirtman et al. 2002; Mu et al. 2007a, b). An in-depth understanding of the ENSO is a pivotal step in achieving this objective (Neelin 1991; Wang and Fang 1996; Jin 1997a, b; Picaut et al. 1997; Wang 2001), where one fundamental issue involves addressing the dynamical system in which ENSO operates (Philander 1990; Moore and Kleeman 1996).

Hypotheses for the ENSO can be loosely grouped into three types. In the first type, El Niño is one phase of a selfsustained, unstable, and naturally oscillatory mode of the coupled ocean-atmosphere system (Zebiak and Cane 1987; Munnich et al. 1991; Timmermann and Jin 2002). In this scenario, nonlinearity plays an important role in controlling 
the ENSO (Jin 1997a, b). In the second type, El Niño is a stable (or damped) mode triggered by random atmospheric "noises" (Peland and Sardeshmukh 1995). Finally, in the third type, El Niño is a self-sustained mode during certain periods, a stable mode during others, or a mixed mode of the two (Wang and Picaut 2004).

An and Jin (2004), Rodgers et al. (2004), and Duan et al. (2004) suggested that the ENSO is a typical nonlinear oscillation system and demonstrated that nonlinearity enhances El Niño and suppresses La Niña and causes the amplitude asymmetry of the ENSO (see also Jin et al. 2003). Furthermore, An and Jin (2004) and Duan and Mu (2006) demonstrated the nonlinear amplitude asymmetry of the ENSO on an interdecadal time scale. Recently, Duan et al. (2009) examined the decaying behavior of El Niño events and illustrated that nonlinearity suppresses the amplitude of El Niño during the decaying phase and favors the decaying of El Niño events; furthermore, the stronger the El Niño event, the more significant the nonlinear effect and the shorter the duration of the decaying phase. These studies emphasized that the ENSO may be controlled by a nonlinear system and fall in the dynamical nonlinearly oscillatory mode of a coupled ocean-atmosphere system. Several types of nonlinearities affect the ENSO (Duan et al. 2008). For example, in the Zebiak-Cane model, ENSO irregularities are assumed to be modulated by the combined effect of nonlinearities arising from temperature advection, wind stress anomaly, and sub-surface water temperature. It is, however, unclear how these types of nonlinearities interact with each other to influence the ENSO and whether their nonlinear effects display a unified effect for all El Niño events. In this paper, we will attempt to address these questions.

As mentioned above, much research has been devoted to studies of the nonlinearities of the ENSO, in which optimal perturbation approaches have been used to reveal the effect of the nonlinearity on the ENSO (Duan et al. 2004, 2009; Duan and $\mathrm{Mu}$ 2006). The so-called optimal perturbation approaches in this study consist of the linear singular vector (LSV; Lorenz 1965) and its nonlinear extension: the conditional nonlinear optimal perturbation (CNOP; $\mathrm{Mu}$ et al. 2003). A comparison of the CNOP with the LSV can reveal the effect of nonlinearity ( $\mathrm{Mu}$ et al. 2003; $\mathrm{Mu}$ and Zhang 2006). The CNOP approach has been applied to study not only the nonlinearities but also the predictability issues of the ENSO ( $\mathrm{Mu}$ and Duan 2003; Duan and $\mathrm{Mu}$ 2006; Mu et al. 2007a, b). These studies mainly focused on exploring the optimal precursors for ENSO events and the spring predictability barrier phenomenon, and they revealed the effect of nonlinearities. The CNOP has been suggested as a useful tool in revealing the nonlinear characteristics of ENSO dynamics and predictability. To determine the optimal precursor for ENSO, Duan et al.
(2004) used the CNOP approach and demonstrated that the CNOP, rather than the LSV, has the highest likelihood to develop into an El Niño event and acts as the optimal precursor for El Niño events. However, the model adopted by Duan et al. was a conceptual one (Wang and Fang 1996; WF96) using only two variables: NIÑO-3 SSTA (the SSTA averaged over the Niño-3 region) and the thermocline depth anomaly (averaged over the Niño-3 region). Consequently, the spatial structure of the optimal precursors for ENSO events could not be explored. Furthermore, the WF96 model only considered the nonlinearities arising from temperature advection and could not be used to study how the different types of nonlinearities described previously interact with each other to influence the ENSO. In the present paper, we will apply the physics of the CNOP as an optimal precursor for El Niño events in the Zebiak-Cane model of intermediate complexity to reveal the spatial pattern of the optimal precursor for El Niño events, and compare the results with those of the LSV to study the effect of nonlinearity on El Niño events; new results are anticipated.

The paper is organized as follows. In Sect. 2, the Zebiak-Cane model is described. Section 3 presents a brief review of the CNOP approach. In Sect. 4, we present the CNOPs of the climatological annual cycle and demonstrate that the CNOPs are most likely to evolve into El Niño events. The effect of nonlinearity on the El Niño events induced by the CNOP and the LSV is revealed in Sect. 5. Finally, a discussion of the results and the conclusions of this study are presented in Sect. 6.

\section{The Zebiak-Cane model}

The Zebiak-Cane model was the first coupled oceanatmosphere model to simulate the observed ENSO interannual variability and has provided a benchmark in ENSO research for over two decades. The Zebiak-Cane model has been widely used in ENSO predictability studies (Zebiak and Cane 1987; Blumenthal 1991; Xue et al. 1994; Chen et al. 2004; Tang et al. 2008). The model is composed of a Gill-type steady-state linear atmospheric model and a reduced-gravity oceanic model, which depict the thermodynamics and atmospheric dynamics of the tropical Pacific with oceanic and atmospheric anomalies near the mean climatological state specified from observations (see Zebiak and Cane 1987).

The atmospheric dynamics are described by the steadystate linear shallow water equations on an equatorial beta plane. The circulation is forced by a heating anomaly that depends partially on local heating that is associated with SST anomalies and partially on low-level moisture convergence (parameterized in terms of the surface wind 
convergence; Zebiak 1986). In this anomaly, convergence feedback is a nonlinear process because the moisturerelated heating occurs only when the total wind field is convergent, which depends not only on the calculated convergence anomaly but also the specified mean convergence. The important effect of the feedback is to focus the atmospheric response to the SST anomalies in or near the regions of mean convergence, particularly the Intertropical Convergence Zone and the Southern Pacific Convergence Zone.

The thermodynamics of this phenomenon are governed by an evolution equation of the SSTA in the tropical Pacific that includes three-dimensional temperature advection by the specified mean currents and the calculated anomalous currents. The assumed surface heat flux anomaly is proportional to the local SST anomaly and constantly adjusts the temperature field toward its climatological mean state, which is specified through observation.

In the model, the atmosphere is first run with the specified monthly mean SST anomalies to simulate monthly mean wind anomalies. Next, the ocean component is enforced by surface wind stress anomalies that are generated from a combination of surface wind anomalies produced by the atmosphere model and the background mean winds.

\section{Conditional nonlinear optimal perturbation}

The CNOP is an initial perturbation that satisfies a given constraint and has the largest nonlinear evolution at the prediction time (described below). The CNOP approach is a natural generalization of the LSV approach to a nonlinear system. For convenience, we briefly review the CNOP approach.

Let $M_{t_{0}, t}$ be the propagator (i.e., the numerical model) of a nonlinear model from initial time $t_{0}$ to $t . u_{0}$ is an initial perturbation superimposed on the basic state $U(t)$, which is a solution to the nonlinear model and satisfies $U(t)=M_{t}\left(U_{0}\right)$, with $U_{0}$ being the initial value of basic state $U(t)$.

For a selected norm $\|\cdot\|$, an initial perturbation $u_{0 \delta}$ is defined as a CNOP if and only if

$J\left(u_{0 \delta}\right)=\operatorname{Max}_{\left\|u_{0}\right\| \leq \delta}\left\|M_{t_{0}, t}\left(U_{0}+u_{0}\right)-M_{t_{0}, t}\left(U_{0}\right),\right\|$

where $\left\|u_{0}\right\| \leq \delta$ is the initial constraint defined by the selected norm $\|\cdot\|$. The norm $\|\cdot\|$ also measures the evolution of the perturbations. We can also investigate situations in which the initial perturbations belong to other types of functional sets. Furthermore, the constraint condition could reflect physical laws that the initial perturbation should satisfy.
For the constraint bound $\delta$, its values should be roughly accordant with the magnitudes of realistic initial perturbations. For example, an El Niño event is thought to be onset when the Niño-3 indices being larger than $0.5{ }^{\circ} \mathrm{C}$ persist for more than 3 months; the initial precursory disturbance of El Niño events should therefore ensure that the Niño-3 indices do not exceed $0.5{ }^{\circ} \mathrm{C}$. That is to say, the value of $\delta$, as a bound of magnitudes of initial precursory disturbances for El Niño events, ought to guarantee that the initial Niño-3 indices are less than $0.5{ }^{\circ} \mathrm{C}$ when we use the CNOP approach to investigate the precursor for El Niño events (Duan et al. 2004). For the optimization period $\left[t_{0}, t\right]$, its length $t-t_{0}$ should be of appropriate magnitude for a nonlinear dynamical system. If the length of the optimization period is too long, the objective function $J$ in the optimization problem (3.1) may be non-smooth due to the strong sensitivity of nonlinearity on initial perturbations, then resulting in the numerical optimizations being difficult to reach the maximum.

The CNOP is characterized by maximum nonlinear evolution of initial perturbations satisfying the given constraint condition (Mu et al. 2003; Mu and Zhang 2006). The CNOP possesses clear physical meanings (Duan and Mu 2009). As mentioned in the introduction, Duan et al. (2004) demonstrated that when the objective function measures the maximum evolution of sea surface temperature anomalies (SSTA) for the ENSO, the resulting CNOP, superimposed on the climatological basic state, acts as the initial anomaly that is most likely to evolve into an El Niño event and represents the optimal precursor to El Niño. The CNOP can also be used to study the initial error with the largest effect on the prediction result at the prediction time (Duan and Mu 2009). In sensitivity analysis studies, the CNOP may represent the least stable mode and can be used to study target observations (Mu et al. 2009).

To compute the CNOP, Eq. (1) must be solved. However, Eq. (1) is a maximization problem, and a method to calculate it directly is currently unavailable. However, several methods are available for calculating minimization problems. Therefore, Eq. (1) was transformed into a minimization problem by considering the negative of the cost function. Accordingly, such methods as Spectral Projected Gradient 2 (SPG2; Birgin et al. 2000), Sequential Quadratic Programming (SQP; Powell 1982) and Limited Memory Broyden-Fletcher-Goldfarb-Shanno (L-BFGS; Liu and Nocedal 1989) could be used to compute the CNOP. In these methods, the gradient of the modified cost function is necessary; furthermore, the adjoint of the corresponding model is usually used to obtain the gradient. With this gradient information, employing these methods with initial estimations can determine the minimum of the modified cost function (i.e., the maxima of the cost function in Eq. (1)) along the descending direction of the 
gradient. In phase space, the point corresponding to the minimum of the modified cost function is the CNOP defined by Eq. (1). In the current paper, we use the SPG2 method to obtain the CNOPs of the Zebiak-Cane model.

To obtain a CNOP, we attempted more than 30 initial random perturbation estimates; if several initial guesses converged to a point in the phase space, this point would be considered a minimum in a given neighborhood. Thus, several points were obtained, and the point that provided the largest cost function in Eq. (1) was considered to be the CNOP.

\section{CNOPs of the climatological annual cycle in the Zebiak-Cane model}

The interannual variations of the coupled system in the core region of the ENSO can be theoretically described by SST and thermocline variations in the Niño-3 region and the wind anomaly over the central Pacific (WF96). Wang et al. (1999) demonstrated that the ENSO displays not only eastern Pacific anomaly patterns but also western Pacific anomaly patterns. Therefore, to utilize the Zebiak-Cane model to determine the optimal precursory disturbance for El Niño events using the CNOP approach, we consider the components of SSTA and thermocline depth anomaly in initial conditions and use a norm associated with the SSTA over the entire tropical Pacific to measure the amplitude of the developed SSTA. Based on these considerations, we select the norm $\|T(\tau)\|_{2}=\sqrt{\sum_{i, j}\left(T_{i, j}(\tau)\right)^{2}}$ to measure the evolution of the SSTA associated with El Niño events. Here, $T(\tau)$ represents the evolution of the SSTA at future time $\tau$ and is obtained by integrating the Zebiak-Cane model from 0 to $\tau$ with initial anomaly $\left(T_{0}, h_{0}\right) . T_{i, j}$ is the SSTA at the grid point $(i, j)$ in the domain of the tropical Pacific with the latitude and longitude from $129.375 \mathrm{E}$ to $84.375 \mathrm{~W}$ by $5.625^{\circ}$ and from $19 \mathrm{~S}$ and $19 \mathrm{~N}$ by $2^{\circ}$, respectively. Using this measurement, we define the objective function associated with the aforementioned CNOP $u_{0 \delta}$ as follows:

$J\left(u_{0 \delta}\right)=\operatorname{Max}_{\left\|u_{0}\right\|_{1} \leq \delta}\|T(\tau)\|_{2}$,

where $u_{0}=\left(w_{1}^{-1} T_{0}, w_{2}^{-1} h_{0}\right)$ is a non-dimensional SSTA and thermocline depth anomaly. $w_{1}=2{ }^{\circ} \mathrm{C}$ and $w_{2}=50^{\circ} \mathrm{m}$ are the characteristic scales of the SST and thermocline depth. $\left\|u_{0}\right\|_{1} \leq \delta$ is the constraint condition defined by a prescribed positive real number $\delta$ and the norm $\left\|u_{0}\right\|_{1}=$ $\sqrt{\sum_{i, j}\left\{\left(w_{1}^{-1} T_{0 i, j}\right)^{2}+\left(w_{2}^{-1} h_{0 i, j}\right)^{2}\right\}}$, where $T_{0 i, j}$ and $h_{0 i, j}$ represent the dimensional SSTA and thermocline depth anomaly at different grid points, respectively.
Next, we compute the CNOPs in the Zebiak-Cane model. We choose the optimization periods of $\tau=3,6,9$, 12 months and the initial times of January, April, July and October to calculate the CNOPs superimposed on the climatological annual cycle of the Zebiak-Cane model. The constraint bound $\delta$ (see Eq. (2)) is experimentally predetermined as $0.6,0.8,1.0,1.2$, and 1.4 , which makes that the initial SSTA at each grid point does not exceed $0.5^{\circ} \mathrm{C}$ and then the initial Niño-3 index is ensured to be less than $0.5{ }^{\circ} \mathrm{C}$. It is shown that for each value of $\delta$, regardless of what the initial time is, there exists one CNOP for each optimization period. All of these CNOPs are on the boundary of the corresponding constraint condition $\left\|u_{0}\right\|_{1} \leq \delta$. That is, the magnitudes of the CNOPs in terms of the chosen norm are always equal to the values of $\delta$. These CNOPs consist of two components: the SSTA and the thermocline depth anomaly. Furthermore, they exhibit similar large-scale patterns of SST and thermocline depth anomalies. In particular, the SSTA components of the CNOPs have a zonal dipolar pattern with positive anomalies in the equatorial eastern Pacific and negative anomalies in the equatorial central-western Pacific, and the thermocline depth anomaly components tend to be positive along the equator.

Figure 1 presents a plot of the SSTA and thermocline depth anomaly components for the CNOPs with January as the initial time, 3 months as the optimization period, and $\delta=0.6$ as the constraint bound. Figure 2 plots the CNOP of the optimization period 12 months and the constraint bound 1.0. It is obvious that the SSTA component of the CNOPs exhibits a strong equatorial eastern-western thermal contrast and is most favorable for a strong westerly anomaly; the thermocline depth anomaly component is positive along the equator and indicates initial warm subsurface water, thereby causing the temperature of the upwelled water to become warmer. Such CNOPs conditions are favorable for the occurrence of an El Niño event.

To verify this inference, we further investigate the evolution of the CNOPs. Integrating the Zebiak-Cane model for one model year with the CNOPs as the initial anomalies provides the SSTA component of the evolution patterns of the CNOPs with lead times of 3, 6, 9, and 12 months and the corresponding thermocline depth and wind stress anomalies. We determine that the CNOPs with $\delta=0.6,0.8,1.0,1.2,1.4$, independent of the initial times and optimization periods, evolve into El Niño-like modes. Furthermore, these CNOPs often attain the SSTA peak at the end of year (i.e., the period from October to December). For example, Fig. 3 presents the evolution patterns of the CNOP of $\delta=1.0$ with January as the initial time and 12 months as the optimization period. The results demonstrate that the initial anomaly of the CNOP structure 
Fig. 1 The CNOPs (LSVs) of the climatological annual cycle for the initial time of January, the optimization period of 3 months and the constraint bound $\delta=0.6$. a CNOP and b LSV. The left column represents the SSTA component, and the right column represents the thermocline depth anomalies

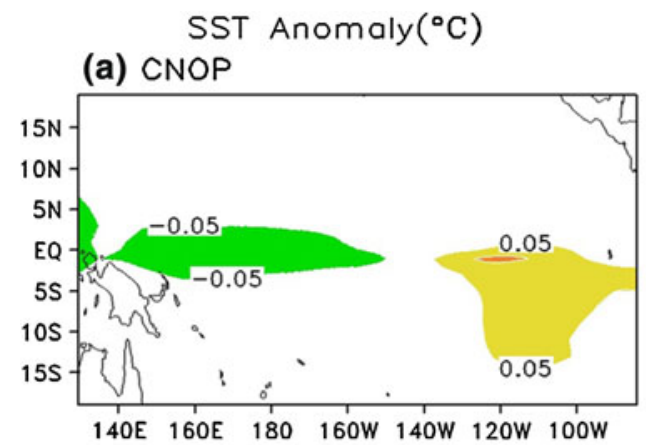

Thermocline Depth Anomaly $(m)$

(b) LSV

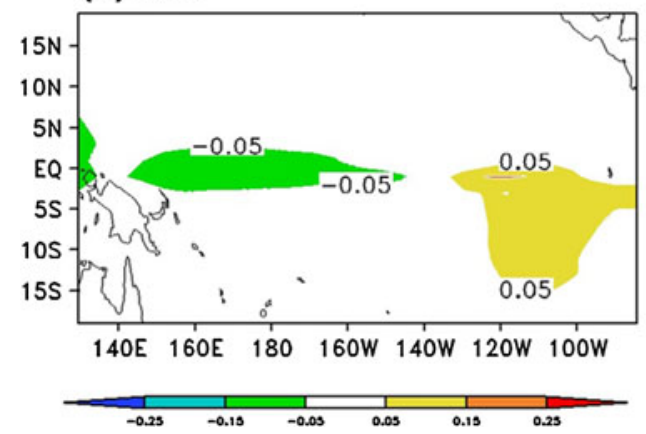

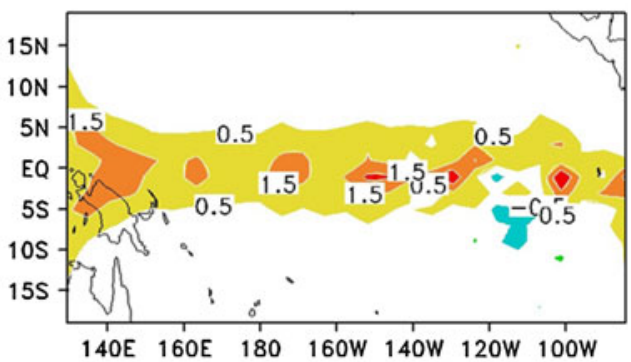

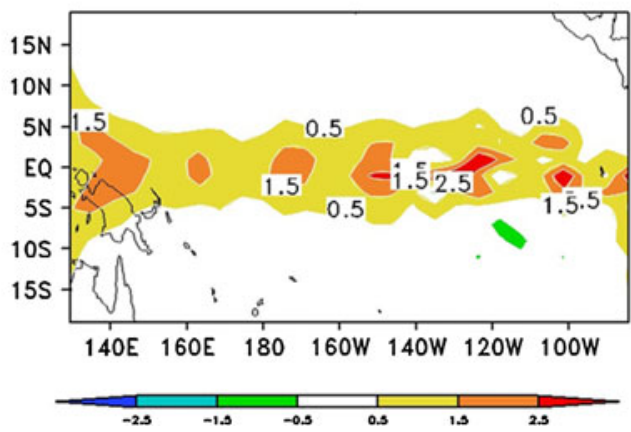

(a) CNOP

SST Anomaly $\left({ }^{\circ} \mathrm{C}\right)$

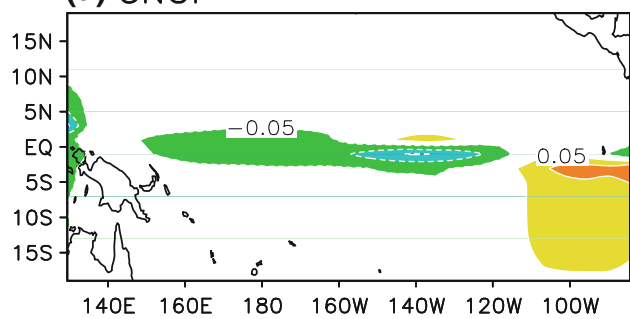

(b) LSV

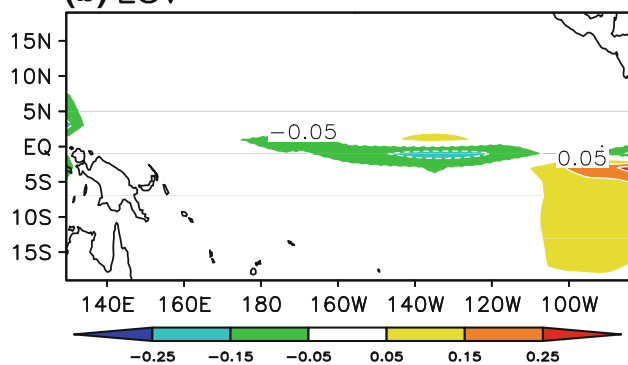

Thermocline Depth Anomaly (m)
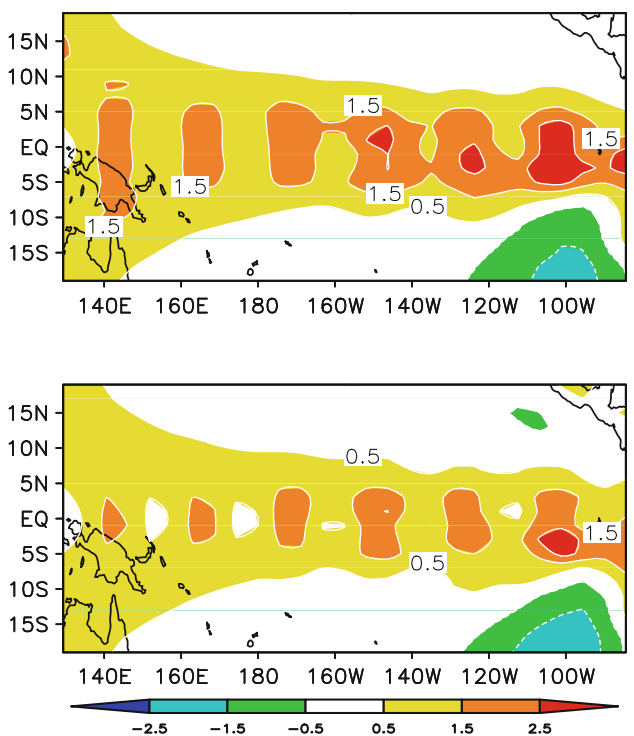

Fig. 2 As in Fig. 1, however for an optimization period of 12 months and the constraint bound $\delta=1.0$

induces westerly anomalies and increasing thermocline depth in the eastern Pacific, which finally causes an El Niño event. To facilitate the description, we refer to these El Niño events as "CNOP-El Niño events". Table 1 lists the Niño-3 SSTA peak values of the CNOP-El Niño events with the initial time January, which indicate the intensities of the El Niño events. From Table 1, it can be observed that when the values of $\delta$ increase from 0.6 to 1.4 , the intensities of the CNOP-El Niño events tend to become much stronger. For other initial times, we obtain similar results (the details are omitted here).

CNOP is a nonlinear extension of the linear singular vector (LSV, which is the fastest growing perturbation in the linearized model). For comparison, we compute the LSVs of the linearized Zebiak-Cane model for optimization periods of $3,6,9$, and 12 months and initial times of January, April, July, and October, respectively. We note that if $u_{0 L}$ is an LSV, the vectors $c u_{0 L}$ ( $c$ is a real number) 

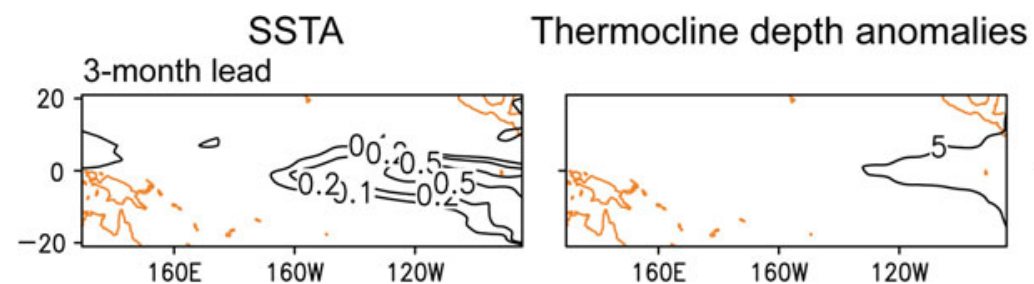

Wind stress anomalies
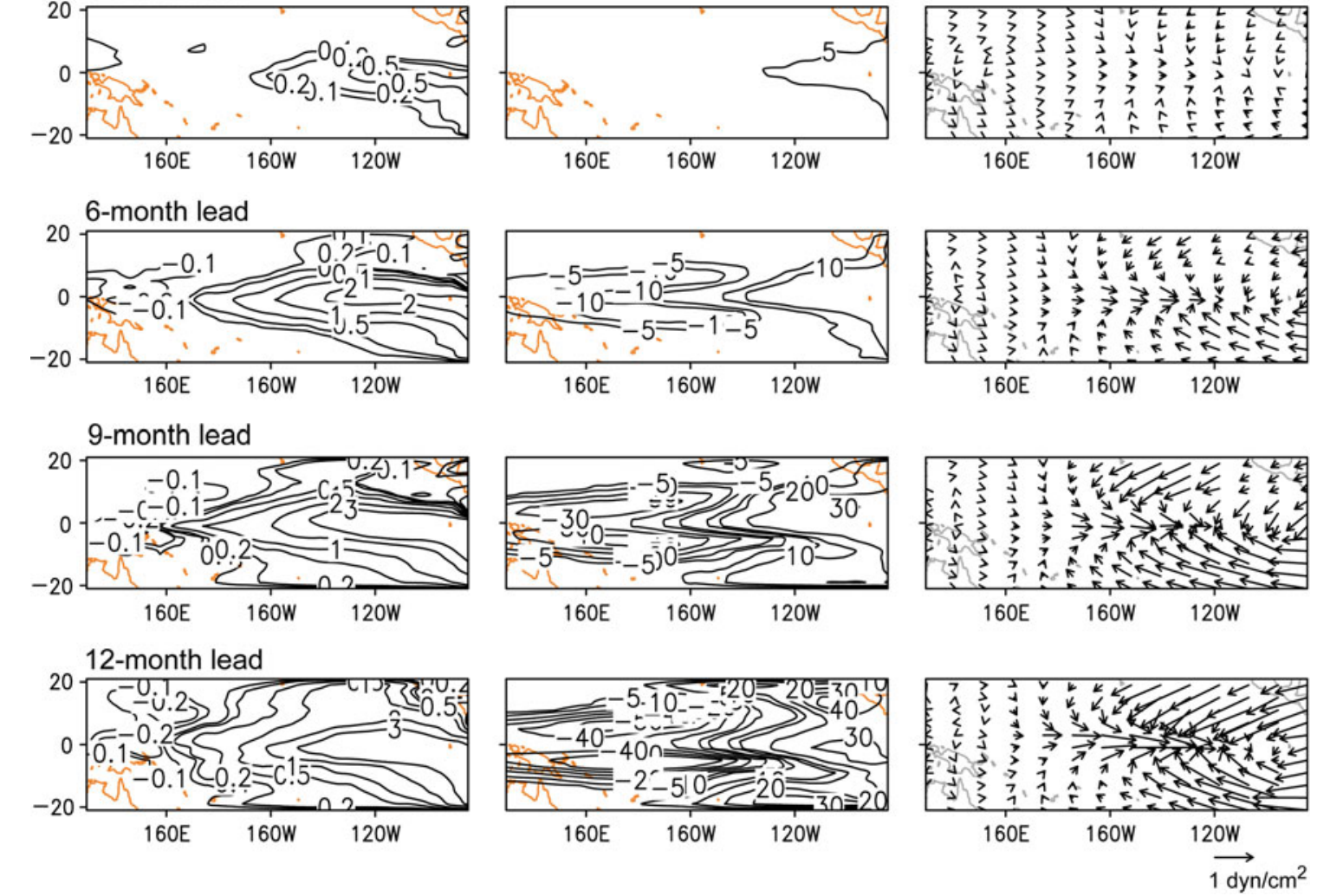

Fig. 3 The evolution patterns of the CNOP for the initial time of January and lead times of 3, 6, 9 and 12 months. The left column represents the SSTA component. The middle column represents the

Table 1 The Niño-3 SSTA peak values of the CNOP- and LSV-El Niño events with $\delta=0.6,0.8,1.0,1.2,1.4$ and optimization periods $3,6,9,12$ months (for initial time January)

\begin{tabular}{lllllll}
\hline$\delta$ & & 0.6 & 0.8 & 1.0 & 1.2 & 1.4 \\
\hline 3 Months & LSV & 1.35 & 1.76 & 2.24 & 2.65 & 3.14 \\
& CNOP & 1.37 & 1.86 & 2.44 & 2.92 & 3.55 \\
6 Months & LSV & 2.13 & 2.49 & 2.90 & 3.04 & 3.31 \\
& CNOP & 2.18 & 2.60 & 3.09 & 3.49 & 3.89 \\
9 Months & LSV & 2.35 & 2.63 & 3.07 & 3.35 & 3.40 \\
& CNOP & 2.42 & 2.89 & 3.38 & 3.64 & 3.82 \\
12 Months & LSV & 2.49 & 2.31 & 2.88 & 2.91 & 2.98 \\
& CNOP & 2.69 & 3.18 & 3.62 & 3.82 & 3.82 \\
\hline
\end{tabular}

are also LSVs with the same growth rate as the LSV $u_{0 L}$. The positive or negative values of $c$ will determine the evolution of the LSV $c u_{0 L}$. For example, if the LSV $u_{0 L}$ develops into an El Niño event, its opposite pattern, $u_{0 L}$ (also an LSV), could evolve into a La Niña event (see Duan et al. 2004). The CNOPs differ from the LSVs. If $u_{0}$ is a $\mathrm{CNOP}, c u_{0}$ may not be a CNOP because of the effect of the thermocline depth anomaly component. The right column represents the corresponding wind stress anomalies

nonlinearities. Therefore, a given CNOP should be compared with the LSV with the same magnitude and sign as the CNOP. For this reason, we define a scaled LSV as follows:

$\hat{u}_{0 L}=(-1)^{N} \frac{\left\|u_{0 \delta}\right\|}{\left\|u_{0 L}\right\|} u_{0 L}, \quad N=1,2$

Thus, $\left\|\hat{u}_{0 L}\right\|=\left\|u_{0 \delta}\right\|$.

If the sign of the LSV $u_{0 L}$ is opposite to (or the same as) that of the CNOP $u_{0}$, the " $N$ " in Eq. (3) is equal to 1 (or 2). Then, the CNOP $u_{0}$ and the scaled LSV $\hat{u}_{0 L}$ have the same signs and magnitudes. The following comparison between the CNOP and the LSV is conducted under this condition.

Computation demonstrates that the LSVs exhibit similar large-scale patterns for different initial time points and optimization periods with the SST component of the positive anomalies in the equatorial eastern Pacific and of the negative anomalies in the equatorial central-western Pacific and with the thermocline depth component of the positive anomalies along the equator. As examples, we plot in Figs. 1 and 2 the corresponding LSVs. It is clear that the CNOPs and the scaled LSVs exhibit similar large-scale 
patterns. However, the LSVs, particularly for the large value of $\delta$ (the large magnitude of the initial anomalies) and the long optimization period, cover a slightly narrower region with a relatively weaker eastern-western thermal contrast and a relatively smaller but positive thermocline depth anomaly. In the Zebiak-Cane model, the LSVs often evolve into El Niño events (the figure is omitted). For convenience, we refer to these LSV-related El Niño events as "LSV-El Niño events". The LSV-El Niño events, particularly for those related to the LSVs with large magnitudes and long optimization periods, are often weaker than the corresponding CNOP-El Niño events (see Table 1). Therefore, particularly for the CNOPs with large magnitudes, it is inferred that the initial anomalies of the CNOP will clearly be more likely to develop into an El Niño event than the anomalies of the LSV. The initial anomalies of the CNOP structure may act as the optimal precursor for El Niño events.

CNOPs are derived from a nonlinear model, whereas LSVs originate from the linearized version of the nonlinear model. The differences between the patterns of the CNOPs with large magnitudes and long optimization periods and those of the LSVs result from the effects of the nonlinearities, finally causing the difference in the intensities of the CNOP- and LSV-El Niño events. This outcome indicates that the El Niño events caused by the CNOPs with larger magnitudes and longer optimization periods are more significantly affected by nonlinearities. How do nonlinearities affect El Niño events? As described in the introduction, several studies have demonstrated that nonlinearities enhance El Niño events (An and Jin 2004; Duan and $\mathrm{Mu}$ 2006). However, in the current paper, we describe a different view based on the CNOP- and LSV-El Niño events in the Zebiak-Cane model. We demonstrate that nonlinearities enhance the CNOP-El Niño events but suppress the LSV-El Niño events (see Sect. 5). Thus, it is possible that certain El Niño events are enhanced by nonlinearities, whereas other El Niño events are suppressed by them. In the next section, we will illustrate this idea by examining the CNOP- and LSV-El Niño events in the Zebiak-Cane model.

To address the behavior of nonlinearities modulating El Nino events, we choose magnitudes of initial perturbations and lengths of optimization periods that should be favorable for revealing the effect of nonlinearities. As shown above, for small values of $\delta$ and short optimization times, the CNOP and LSV patterns are trivially different, and the intensities of the CNOP- and LSV-El Niño events are almost the same. Furthermore, we also conduct numerical experiments to determine whether an optimal constraint bound $\delta$ exists that induces the largest growth rate of developed SSTA caused by the CNOPs and find that the smaller the values of $\delta$, the larger the growth rate (the details are omitted). That is to say, for $\delta$ ranging from 0.6 to 1.4 , the growth rate is the largest when $\delta=0.6$. However, for this small value of $\delta$, as mentioned above, the resultant CNOP and LSV patterns are very similar and cannot reveal the effect of nonlinearities. In fact, the LSVs just describe the initial perturbations that have the largest growth rate for the developed SSTA under the condition that the initial perturbations are sufficiently small and the optimization periods are sufficiently short (Mu et al. 2003). That is to say, for the sufficiently small initial perturbations and optimization periods, the CNOPs may be approximated by LSVs. In this case, the effect of nonlinearity is very small. This paper focuses on the effect of nonlinearities on El Niño's dynamical behavior. Therefore, we adopt large values of $\delta$ and long optimization periods to obtain the CNOPs, which, as demonstrated in last few paragraphs, creates the largest differences between CNOP and LSV and contributes to testing the effect of nonlinearities. In particular, in this paper, we choose an optimization period of 12 months. Meanwhile, we observe that when the optimization period is 12 months, the CNOP-El Niño events tend to possess the same intensities (i.e., the Niño-3 indices at the peak phase converge to approximately $3.8^{\circ} \mathrm{C}$ ) when the initial constraint $\delta$ is larger than 1.0 (see Table 1). Furthermore, in numerical experiments, we find that the results of $\delta=1.0$ are similar to those of $\delta=1.2$ and 1.4 (the details are omitted). Therefore, in the next section, we choose the CNOPs with the initial constraint bound $\delta=1.0$ and the optimization period of 12 months to address the behaviors of the nonlinearity that modulates El Niño events.

To find the optimal precursor for El Nino events, the choice of the magnitudes of initial anomalies (i.e., values of $\delta$ ) should physically require the initial SSTA at each grid point to be less than $0.5{ }^{\circ} \mathrm{C}$, and then the initial Niño-3 index will be less than $0.5^{\circ} \mathrm{C}$. The constraint condition $\left\|u_{0}\right\|_{1} \leq \delta$ with $\delta=1.0$ chosen in this paper satisfies this requirement, which implies that the initial SSTA and thermocline depth anomaly measured by the selected norm do not exceed 1.0 (a dimensional SSTA of $2.0^{\circ} \mathrm{C}$ and a thermocline depth anomaly of $50 \mathrm{~m}$ ). Furthermore, the results obtained from $\delta=1.0$ are similar to those for $\delta=1.2$ and 1.4 (see last paragraph). However, for much large values of $\delta$, the resultant CNOPs have initial SSTA values that are larger than $0.5{ }^{\circ} \mathrm{C}$, which may indicate an $\mathrm{El}$ Niño event has begun. In this case, treating the corresponding CNOPs as precursors for El Niño events does not make sense. Therefore, we do not adopt much larger values of $\delta$ to study the effect of nonlinearity. These discussions physically elucidate the choice of the values of the constraint bound $\delta$ used in the next section. 


\section{How do the nonlinearities modulate the CNOP- and LSV-EI Niño events?}

We integrate the Zebiak-Cane model and its linearized version with the CNOPs of $\delta=1.0$ and an optimization period of 12 months as the initial conditions and derive the CNOP-El Niño events (Fig. 3) and the evolution of the CNOPs in the linearized Zebiak-Cane model. For simplicity, we refer to the evolution of the CNOP in the linearized Zebiak-Cane model as the linearized CNOP-El Niño event. It is inferred that the differences between the CNOP-El Niño event and the linearized CNOP-El Niño events could reveal the effect of nonlinearities on the CNOP-El Niño events. Table 2 presents the intensities of the CNOP-El Niño events and their linearized CNOP-El Niño events. The CNOP-El Niño events are often observed to be stronger than the linearized CNOP-El Niño events. The result indicates that the nonlinearities in the ZebiakCane model enhance the linearized CNOP-El Niño events, which corresponds to the results of previous studies (see introduction). However, for the LSV-El Niño events, the nonlinearities exhibit different effects compared with the CNOP-El Niño events.

For the LSV-El Niño events, we performed numerical experiments similar to those performed for the CNOP-El Niño events. We integrate the Zebiak-Cane model and the linearized Zebiak-Cane model with the LSVs (whose magnitudes are the same as those of the CNOPs) as the initial anomalies and obtain the LSV-El Niño events and the linearized LSV-El Niño events. The results demonstrate that the Niño-3 SSTAs of the linearized LSV-El Niño events are typically larger than those of the LSV-El Niño events (see Table 3), indicating that the nonlinearities often suppress the linearized LSV-El Niño events.

For different El Niño events, the nonlinearities may modulate the events in a different manner. As demonstrated above, the CNOP-El Niño events are often stronger than the linearized CNOP-El Niño events. Therefore, the nonlinearities enhance the linearized CNOP-El Niño events, whereas the LSV-El Niño events are typically weaker than the linearized LSV-El Niño events (i.e., the nonlinearities suppress the linearized LSV-El Niño events). In the
Zebiak-Cane model, the nonlinearities result from three factors: temperature advections, sub-surface temperature parameterization, and wind stress anomalies. For these types of nonlinearity, it is necessary to address the manner with which each type of nonlinearity modulates El Niño events and which type of nonlinearity plays a dominant role.

To address these questions, we perform two groups of sensitivity experiments. One group is associated with the CNOP-El Niño events. The other group is related to the LSV-El Niño events. In these two groups of experiments, we adopt the differences between the temperature advections (subsurface temperature and wind stress anomalies) in the Zebiak-Cane model and those in the linearized ZebiakCane model and use their signs to indicate the tendency of the effect of the nonlinearities in the temperature advections (subsurface temperature parameterization and wind stress anomalies) on the El Niño events (see the Appendix). To facilitate the discussion, we denote the nonlinear effect of the temperature advection as NTA, that of the subsurface temperature parameterization as STP, and that of the wind stress anomalies as WSA.

In the first group of experiments (the CNOP-El Niño events), the nonlinear terms associated with NTA, WSA, and STP in the Zebiak-Cane model are linearized, whereas the other two nonlinear terms remain unchanged. Accordingly, we obtain three partially linearized Zebiak-Cane models with linearized NTA, a linearized WSA and linearized STP. For convenience, the three partially linearized models are denoted as the L-NTA, L-WSA, and L-STP models. Integrating these models for 1 year with the CNOPs as the initial conditions, we obtain the corresponding partially linearized CNOP-El Niño events, i.e., the NTA-linearized, WSA-linearized, and STP-linearized CNOP-El Niño events. We determined that the CNOP-El Niño events are often stronger than the NTA-linearized CNOP-El Niño events but weaker than the WSA- and STPlinearized CNOP-El Niño events (see Table 2). In Fig. 4, we plot the evolution patterns of the NTA-, STP-, and WSA-linearized CNOP-El Niño events for the initial time of January. In Fig. 5, we illustrate the time evolution of the Niño-3 SSTA (or the Niño-3 index) for these El Niño

Table 2 The Niño-3 indices of CNOP-El Niño, linearized CNOP-El Niño and NTA-, WSA-, and STP-linearized CNOP-El Niño at El Niño's peak phase

\begin{tabular}{llllll}
\hline $\begin{array}{l}\text { Initial } \\
\text { times }\end{array}$ & $\begin{array}{l}\text { CNOP-El } \\
\text { Niño }\end{array}$ & $\begin{array}{l}\text { Linearized CNOP-El } \\
\text { Niño }\end{array}$ & $\begin{array}{l}\text { NTA-linearized CNOP-El } \\
\text { Niño }\end{array}$ & $\begin{array}{l}\text { WSA-linearized CNOP-El } \\
\text { Niño }\end{array}$ & $\begin{array}{l}\text { STP-linearized CNOP-El } \\
\text { Niño }\end{array}$ \\
\hline January & 3.62 & 1.78 & 2.27 & 4.36 & 4.14 \\
April & 2.68 & 2.14 & 2.10 & 3.07 & 3.05 \\
July & 2.70 & 1.17 & 1.62 & 3.52 & 3.41 \\
October & 3.36 & 2.38 & 2.23 & 4.03 & 4.09 \\
\hline
\end{tabular}


Table 3 The Niño-3 indices of LSV-El Niño, linearized LSV-El Niño and NTA-, WSA-, and STP-linearized LSV-El Niño at El Niño's peak phase

\begin{tabular}{llllll}
\hline $\begin{array}{l}\text { Initial } \\
\text { times }\end{array}$ & $\begin{array}{l}\text { LSV-El } \\
\text { Niño }\end{array}$ & $\begin{array}{l}\text { Linearized LSV-El } \\
\text { Niño }\end{array}$ & $\begin{array}{l}\text { NTA-linearized LSV-El } \\
\text { Niño }\end{array}$ & $\begin{array}{l}\text { WSA-linearized LSV-El } \\
\text { Niño }\end{array}$ & $\begin{array}{l}\text { STP-linearized LSV-El } \\
\text { Niño }\end{array}$ \\
\hline January & 2.88 & 2.94 & 2.28 & 3.79 & 3.43 \\
April & 1.57 & 2.44 & 1.47 & 1.81 & 1.74 \\
July & 1.31 & 1.96 & 1.14 & 1.52 & 1.60 \\
October & 2.76 & 3.45 & 1.81 & 4.08 & 3.55 \\
\hline
\end{tabular}

events. It is shown that only when the Niño-3 SSTA evolves to become large, the NTA-linearized CNOP-El Niño event becomes gradually weaker than the CNOP-El Niño event, whereas the WSA- and the STP-linearized CNOP-El Niño events tend to become gradually stronger than the CNOP-El Niño event. These results indicate that the linearization of the NTA favors a weaker El Niño event, whereas the linearization of the WSA and the STP favors a stronger El Niño event. That is, the nonlinearity in the NTA enhances the El Niño events, whereas the nonlinearities from the WSA and STP suppress the El Niño events.

The nonlinearities associated with temperature advection, i.e., NTA, which is measured by the differences between the temperature advections (including the linear and nonlinear temperature advection terms; see the Appendix) in the Zebiak-Cane model and those in the L-NTA model (see the Appendix), induce a positive effect of nonlinearity during El Niño development (see the left column in Fig. 6) and therefore enhance the El Niño events. Physically, the NTA is predominantly related to the anomalous zonal SST gradient and the anomalous vertical temperature gradient (see Wang and Fang 1996). Duan et al. (2008) demonstrated that both the anomalous zonal SST difference and the vertical temperature difference tend to increase with the development of El Niño, and the NTA gradually increases. Thus, during an El Niño event, when the SSTA increases, the warming in the eastern Pacific increases the zonal SST difference and the anomalous westerly, which weaken the anomalous upwelling. (a) CTL 3-month lead

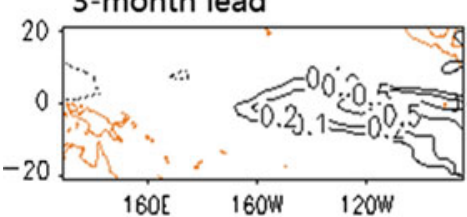

(b) L-NTA

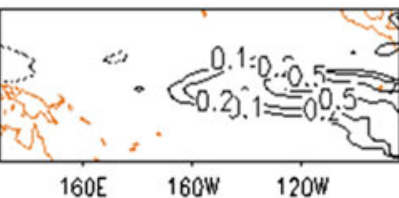

6 -month lead
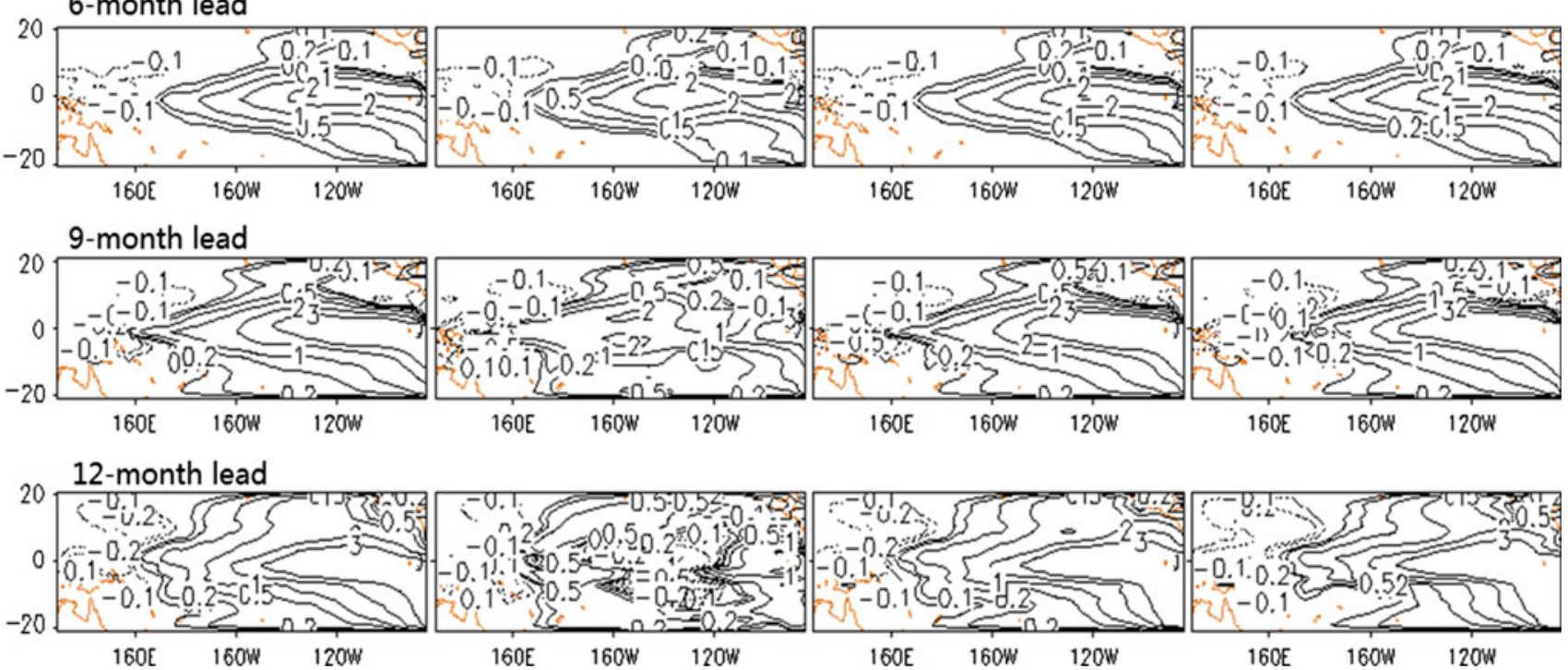

Fig. 4 The SSTA components of a the CNOP-El Niño events with January as the initial time, $\mathbf{b}$ the NTA-linearized CNOP-El Niño events, $\mathbf{c}$ the STP-linearized CNOP-El Niño events, and $\mathbf{d}$ the WSA-linearized CNOP-El Niño events 
Fig. 5 The time evolutions of the Niño-3 SSTA for a CNOPEl Niño events, linearized CNOP-El Niño events, and NTA-, STP-, and WSAlinearized CNOP-El Niño events with the initial time of January and b LSV-El Niño event, linearized LSV-El Niño events, and NTA-, STP-, and WSA-linearized LSV-El Niño events. When the Niño-3 SSTA of the CNOP-El Niño event becomes gradually large after August, the CNOP-El Niño event is significantly stronger (weaker) than the NTAlinearized CNOP-El Niño events but slightly weaker than the WSA- and STP-linearized CNOP-El Niño events, which indicates that the NTA strongly enhances the El Niño events, whereas the WSA and STP slightly suppress it. For the LSV-El Niño events, although the NTA also enhances them and the WSA and STP suppress them when the Niño-3 SSTA of the LSV-El Niño event becomes gradually large after September, the amplitude of the NTAlinearized LSV-El Niño event, which is weaker than the LSVEl Niño event, is significantly smaller than that of the NTAlinearized CNOP-El Niño event, which is weaker than the CNOP-El Niño event. This fact indicates that the enhancement of the NTA in the linearized LSV-El Niño events is smaller than the combined effect of the suppression from the nonlinearities of the WSA and STP, which finally leads to a combined effect of the three types of nonlinearities that suppresses the LSV-El Niño event
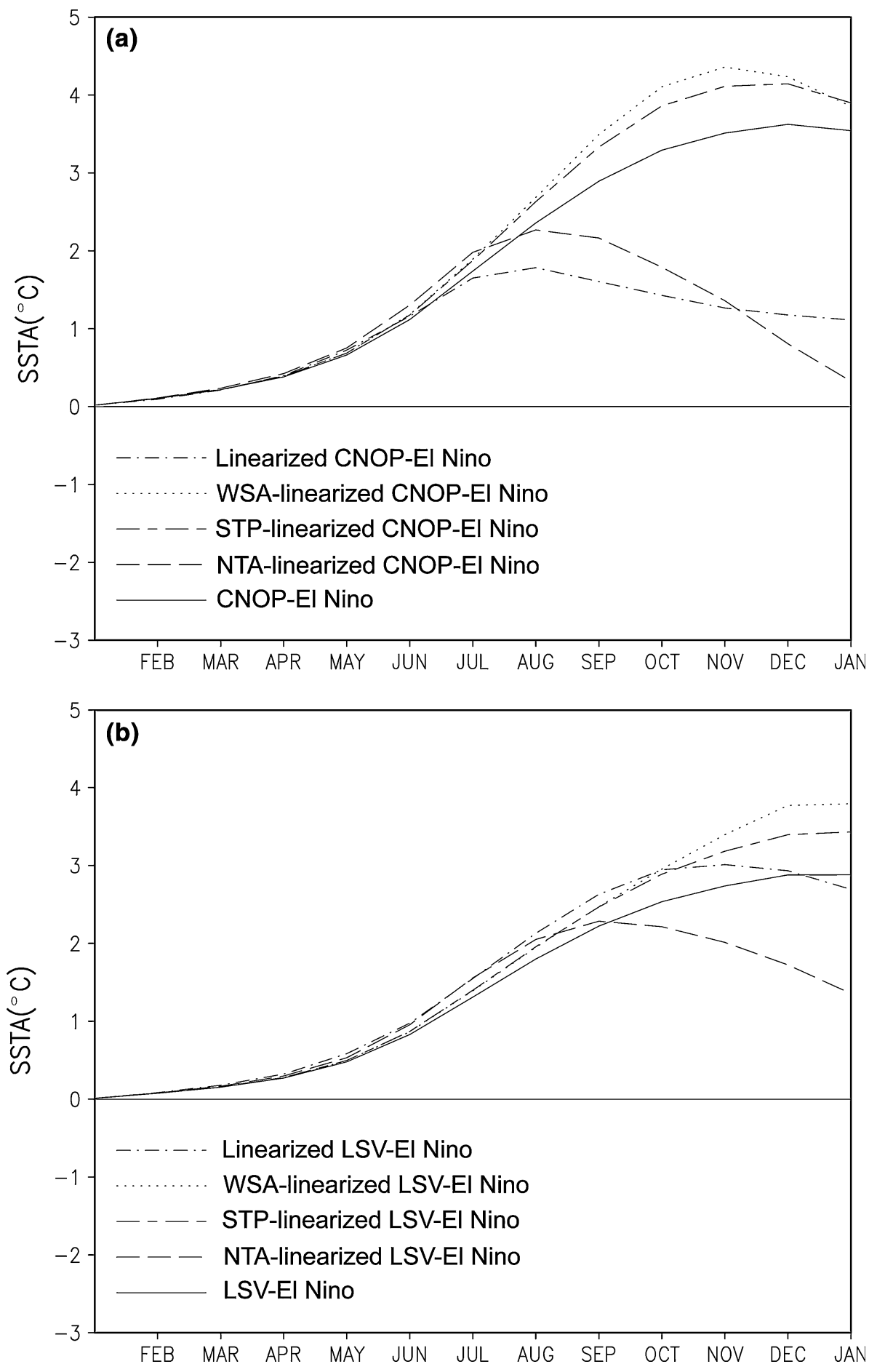

The weak anomalous upwelling acts on the increasing anomalous vertical temperature difference and favors the strengthening of El Niño, which implies that nonlinearities in the NTA enhance El Niño. The WSA tends to be positive during an El Niño event, that is, a westerly anomaly. However, the nonlinearity of the WSA, which is measured as the difference between the WSA in the Zebiak-Cane model and that in the L-WSA model (see the Appendix), presents an easterly effect (see the right column in Fig. 6), which weakens the westerly anomaly and favors a weaker El Niño event. In other words, the nonlinearities in the WSA suppress El Niño. Meanwhile, we find that the linearized subsurface temperature (i.e., the STP in the L-STP model) for El Niño is higher than in the Zebiak-Cane model (see the middle column in Fig. 6). Specifically, the subsurface temperature increases because of the 
linearization. As a result, the temperature of the upwelled water is higher in the L-STP model, which will cause a much stronger El Niño event in comparison with the Zebiak-Cane model. Additionally, the nonlinearities related to the STP suppress El Niño.

The differences of the intensities between the CNOP-El Niño events and the linearized CNOP-El Niño events indicate that the combined effect of the three types of nonlinearity enhances the linearized CNOP-El Niño event. Therefore, it is inferred that the enhancement of the NTA in the linearized CNOP-El Niño events is considerably larger than the combined effect of the suppression from the nonlinearities of the WSA and STP. This result can be observed in Figs. 4 and 5. In fact, the El Niño-like events in the L-NTA model (i.e., the NTA-linearized CNOP-El Niño events) are significantly weaker than the CNOP-El Niño events, whereas the El Niño-like events in the L-STP and L-WSA models (i.e., the STP- and WSA-linearized CNOP-El Niño events) are slightly stronger than the CNOP-El Niño events. The NTA significantly enhances El Niño events. However, the STP and WSA slightly suppress
El Niño events, resulting in a combined effect in the Zebiak-Cane model that enhances the linearized CNOP-El Niño events. The NTA plays a dominant role in shaping how nonlinearities modulate the CNOP-El Niño events.

The second group of experiments examines the LSV-El Niño events (see Table 3 and Fig. 5). We demonstrate that although the NTA in the LSV-El Niño case favors stronger El Niño events and the WSA and STP favor weaker El Niño events, the combined effect of the WSA and STP is more significant than the effect of the NTA when the Niño3 SSTA evolves to become large. The enhancement of the NTA on the linearized LSV-El Niño events is weaker than the combined suppressive effect of the WSA and STP. Consequently, the combined effect of the nonlinearities in the Zebiak-Cane model is the suppression of the linearized LSV-El Niño events. The combined effect of the STP and the WSA plays a significant role in determining how nonlinearities modulate the LSV-El Niño events.

In summary, the NTA enhances the evolution of El Niño events, whereas the WSA and the STP tend to suppress El Niño events. In particular, for the CNOP-El Niño events,
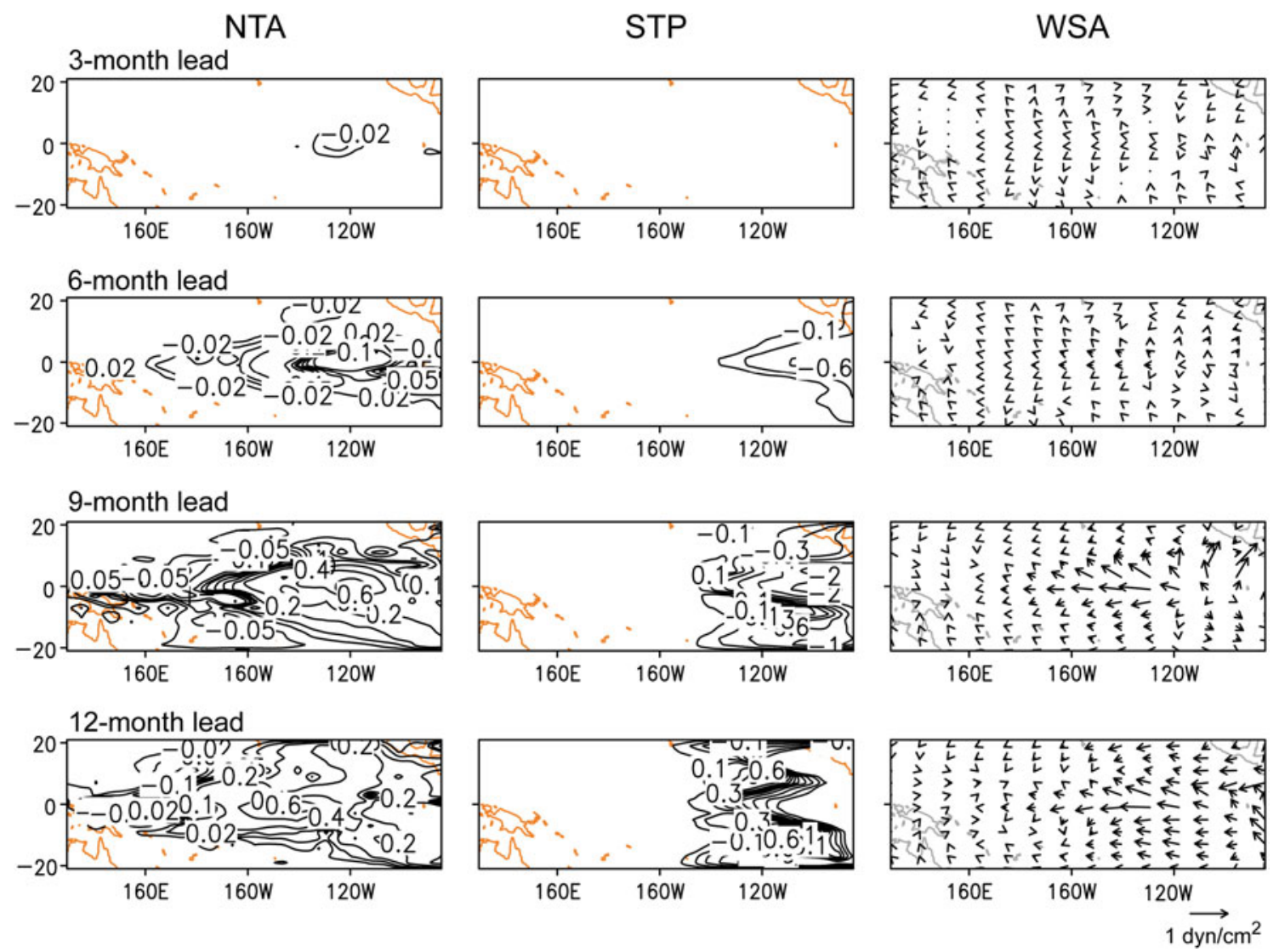

Fig. 6 Tendency of the effect on the CNOP-El Niño event demonstrated in Fig. 2 of nonlinearities arising from temperature advection (NTA; left column), sub-surface temperature parameterization (STP; middle column), and wind stress anomalies (WSA; right column). The
NTA (STP and WSA) is measured by the differences between the temperature advections (subsurface temperature and wind stress anomalies) in the Zebiak-Cane model and that in the linearized Zebiak-Cane model 
the effect of the NTA on El Niño events is significantly larger than that of the combined effect of the WSA and the STP, resulting in the increased strength of the CNOP-El Niño events relative to the linearized CNOP-El Niño events. However, for the LSV-El Niño events, the effect of the NTA on El Niño events is weaker than the combined effect of the WSA and the STP, which results in the decreased strength of the LSV-El Niño events relative to the linearized LSV-El Niño events.

\section{Conclusions and discussions}

In the context of an intermediate Zebiak-Cane model, the effects of nonlinearities on ENSO events are investigated by exploring optimal precursory disturbances. We first compute the CNOP and the LSV of the climatological annual cycle in the Zebiak-Cane model and observe the differences in their patterns. The CNOP consists of the components of the SSTA and the thermocline depth anomalies. The SSTA contains a strong eastern-western thermal contrast with positive anomalies in the equatorial eastern Pacific and negative anomalies in the equatorial central-western Pacific, which have the potential to create a strong westerly anomaly. The thermocline depth anomaly component is positive along the equator and indicates initial warm subsurface water, which favors increases in the temperature of the upwelled water. Such conditions for the CNOP strongly favor the onset of an El Niño event. The LSV has a structure similar to that of the CNOP but covers a slightly narrower region because of the absence of nonlinearities, particularly for the LSVs with large magnitudes. The LSV is derived from the SSTA component with relatively weak eastern-western thermal contrasts and relatively low subsurface temperatures, which induce a relatively weak westerly anomaly and lead to weaker El Niño events compared with the CNOP. Therefore, the CNOP, rather than the LSV, may be the optimal precursory disturbance of El Niño events.

The CNOP and the LSV, as two initial anomalies, evolve into two El Niño events with different intensities, i.e., the CNOP- and LSV-El Niño events. We observe that nonlinearities affect the CNOP-El Niño and LSV-El Niño events in different manners. Specifically, nonlinearities enhance the CNOP-El Niño events but suppress the LSVEl Niño events. The nonlinear effect on the El Niño events in the Zebiak-Cane model results from temperature advection (NTA), subsurface temperature parameterization (STP), and wind stress anomalies (WSA). By exploring the role of these nonlinearities in modulating El Niño events, we determined that the NTA enhances El Niño events, whereas the WSA and the STP tend to have a suppressive effect on them. In particular, for the CNOP-El Niño events, the enhancement effect of the NTA is stronger than the combined suppression effect of the WSA and the STP, thereby causing the CNOP-El Niño events to possess larger amplitudes than the linearized CNOP-El Niño events. The NTA plays a dominant role in modulating the CNOP-El Niño events. However, for the LSV-El Niño events, the combined suppression effect of the WSA and the STP is larger than the enhancement effect of the NTA during the growth phase of the linearized LSV-El Niño event. Thus, the linearized LSV-El Niño event is suppressed by the nonlinearities observed during its growth phase.

Considering that the ENSO is related to the eastern and western Pacific anomaly patterns, in this paper, we use the norm associated with the SSTA over the entire tropical Pacific to measure the amplitude of the developed SSTA in the attempt to obtain the CNOPs. Additionally, in numerical experiments, we examine the CNOPs with the Niño-3 index as a measurement of the developed SSTA. We find that the CNOPs with these two measurements are highly similar. Furthermore, the corresponding LSVs, particularly for those with large magnitudes and long optimization periods, cover a slightly narrower region with a relatively weaker eastern-western thermal contrast and a relatively smaller but positive thermocline depth anomaly. It is inferred that the resulting effect of the nonlinearities on El Niño obtained by the norm associated with the SSTA over the entire tropical Pacific will be similar to the effect that is identified by the measurement of the Niño-3 index. In fact, the El Niño events in the Zebiak-Cane model are most sensitive to the SSTA in the Niño-3 region, and the evolutions of these El Niño events are dominated by the positive SSTA in the Niño-3 region despite the existence of the western Pacific anomalies (Wang et al. 1999). Therefore, although we adopt the norm associated with the SST anomalies over the entire tropical Pacific, results similar to the measurement of the Niño-3 index are expected to be obtained. For the sake of simplicity, in this paper, we only show the results of the norm associated with the SSTA over the entire tropical Pacific.

To address the effect of nonlinearities on El Niño events, we adopt the CNOPs and LSVs with large magnitudes, e.g., $\delta=1.0$, and long optimization periods, e.g., 12 months. Additionally, in numerical experiments, we examine the CNOPs and LSVs with different magnitudes (values of $\delta$ ) and optimization periods and demonstrate that when their magnitudes are much larger (for example, $\delta=1.2,1.4$ ), the effect of nonlinearities on their induced El Niño events are similar to that of the El Niño events associated with $\delta=1.0$. That is, nonlinearities enhance the CNOP-El Niño events but suppress the LSV-El Niño events. Furthermore, we also demonstrate that when the initial constraints $\delta$ are sufficiently small and the optimization periods are sufficiently short, the CNOPs and 
LSVs exhibit almost identical patterns, and consequently the CNOP- and LSV-El Niño events possess almost the same intensity. Moreover, CNOP- and LSV-El Niño events with small values of $\delta$ are much weaker than those with large values of $\delta$. In this case, although nonlinearities still enhance the CNOP-El Niño events and suppress the LSVEl Niño events, the amplitudes of the nonlinear effects are negligible, causing the CNOPs and LSVs to be nearly identical and the CNOP- and LSV-El Niño events to possess almost the same intensities. This paper focuses on the investigation of the different behaviors of the nonlinearities that modulate CNOP- and LSV-El Niño events. Furthermore, the nonlinearities are typically associated with strong El Niño events. Therefore, to ensure that the corresponding El Niño events are sufficiently strong to reveal the effect of the nonlinearities, we selected a relatively large value of $\delta$ (i.e., $\delta=1.0$ ) to obtain CNOPs and LSVs as well as CNOP- and LSV-El Niño events with sufficiently large intensities. For optimization periods longer than 12 months (for example, 15 months), we also test the results. We find that the 30 initial perturbation estimates in the optimization solver did not converge to any point in phase space (see Sect. 3) and then fail to reach a CNOP. The possible reason is that the sensitivity of nonlinearity to initial perturbations is sufficiently strong for much long optimization periods such that the objective function associated with CNOPs becomes non-smooth and the numerical optimization is then difficult to capture the minimum. Therefore, in the current paper we choose optimization period as 12 months to address the effect of nonlinearity on El Niño events.

Other studies have used the Zebiak-Cane model to study LSVs (Xue et al. 1997; Cheng et al. 2009). Cheng et al. (2009) considered only the initial uncertainties in the SSTA and calculated LSVs. The LSVs in the study by Cheng et al. (2009) are highly similar to the SSTA component of the LSVs with a combined mode of the SSTA and thermocline depth anomaly presented in this paper. That is, the SSTA displays a large-scale dipolar pattern with negative anomalies in the central-western Pacific and positive anomalies in the eastern Pacific. The present study further investigates the pattern of the thermocline depth anomaly component and its role in El Niño development. In addition, the LSVs in the study by Cheng et al. (2009) are used to study the error growth associated with ENSO predictability, whereas those in the present study are adopted to study the optimal precursory disturbance of El Niño events. Furthermore, the present study, considering the linearity of a singular vector, used CNOP to investigate the optimal precursors of El Niño events and identify the effect of nonlinearity. In any case, the similarities between the LSVs in the study by Cheng et al. (2009) and those in the present study establish the reasonability of this study.

In addition, Xue et al. (1997) considered the initial uncertainties of the SSTA, the thermocline depth anomaly, and wind and obtained LSVs superimposed on an annual cycle. On a large spatial scale, these LSVs display patterns that are similar to those in the present study. However, certain differences are present on much smaller spatial scale. Such differences may result from the different norms used to measure the growth of the perturbation in these two studies. Which norm is more physically reasonable is an open question that should be investigated in the future. Another possible reason for the differences is that the algorithms used for computing the LSVs are different in the two studies. Nevertheless, for the norm adopted in the present study, we randomly selected a large number of initial perturbations in the neighborhood of the LSVs (or the CNOPs) to perform the sensitivity experiments and observed that the LSVs (or the CNOPs) grow much faster than these perturbations in the linearized Zebiak-Cane model (or the Zebiak-Cane model). The LSVs (or the CNOPs) in the present study could be the initial anomalies that are most likely to evolve into El Niño events in the linearized Zebiak-Cane model (or the Zebiak-Cane model); i.e., the sensitivity experiments demonstrate that the CNOPs and the LSVs are the optimal perturbation in the ZebiakCane model and its linearized model, respectively. Furthermore, the CNOPs and the LSVs are physically acceptable.

As described above, in this paper, we use the ZebiakCane model of intermediate complexity to study the behavior of nonlinear effects on El Niño events. The results indicate that the nonlinearities enhance certain El Niño events but suppress others. The simplicity of the adopted model may limit its ability to simulate real systems. Thus, the resultant nonlinear behaviors associated with El Niño events are indicative of real systems. Furthermore, because the main characteristics of La Niña events, e.g., the phaselocking characteristic, cannot be well modeled by the Zebiak-Cane model (An and Wang 2001), no attempt has been made in the present study to investigate the corresponding problem for La Niña events. To validate the results of this paper, it would be interesting to examine the nonlinear behaviors in models of higher complexity, such as full GCMs, and to perhaps use the observation data.

Acknowledgments We wish to thank two anonymous reviewers for their insightful comments and constructive suggestions. This work was jointly sponsored by the National Basic Research Program of China (Nos. 2012CB955202 and 2010CB950400), the Knowledge Innovation Program of the Chinese Academy of Sciences (No. KZCX2-YW-QN203), and the National Natural Science Foundation of China (No. 41176013). 
Open Access This article is distributed under the terms of the Creative Commons Attribution License which permits any use, distribution, and reproduction in any medium, provided the original author(s) and the source are credited.

\section{Appendix: Measuring the effect of the nonlinearities associated with NTA, STP, and WSA in the Zebiak- Cane model}

1. The temperature advections in the Zebiak-Cane model

$$
\begin{aligned}
\Psi= & -\bar{u} T_{x}-\bar{v} T_{y}-\gamma M(\bar{w}) T_{z}-u \bar{T}_{x}-v \bar{T}_{y}-\gamma\{M(\bar{w}+w) \\
& -M(\bar{w})\} \bar{T}_{z}-u T_{X}-v T_{y}-\gamma\{M(\bar{w}+w)-M(\bar{w})\} T_{z},
\end{aligned}
$$

where $T, u, v, w$ denote anomalies of mixed layer temperature (or SST), horizontal surface zonal and meridional velocity, and the upwelling at the mixed layer base, respectively; the bar denotes the climatological mean.

The temperature advections in the L-NTA model:

$$
\begin{aligned}
\Psi^{\prime}= & -\bar{u} T_{x}^{\prime}-\bar{v} T_{y}^{\prime}-\gamma M(\bar{w}) T_{z}^{\prime}-u^{\prime} \bar{T}_{x}-v^{\prime} \bar{T}_{y} \\
& -\gamma\left\{M\left(\bar{w}+w^{\prime}\right)-M(\bar{w})\right\} \bar{T}_{z},
\end{aligned}
$$

where the prime denotes the variables in the linearized model.

The tendency of the effect of the nonlinearities associated with temperature advections (NTA) on El Niño is indicated by the signs of $\Psi-\Psi^{\prime}$.

2. The subsurface temperature parameterization in the Zebiak-Cane model:

$T_{\text {sub }}= \begin{cases}T_{1}\left\{\tanh b_{1}[\bar{h}+h]-\tanh \left(b_{1} \bar{h}\right)\right\}, & h>0 \\ T_{2}\left\{\tanh b_{2}[\bar{h}+h]-\tanh \left(b_{2} \bar{h}\right)\right\}, & h<0 .\end{cases}$

The subsurface temperature parameterization in the L-STP model:

$T_{\text {sub }}^{\prime}= \begin{cases}T_{1}^{\prime} b_{1} h^{\prime} / \cosh ^{2}\left(b_{1} \bar{h}\right), & h^{\prime}>0 \\ T_{2}^{\prime} b_{2} h^{\prime} / \cosh ^{2}\left(b_{2} \bar{h}\right), & h^{\prime}<0 .\end{cases}$

The tendency of the effect of nonlinearities associated with subsurface temperature parameterization (STP) on El Niño is indicated by the signs of $T_{\text {sub }}-T_{s u b}^{\prime}$, where $T, h$ are the SST and thermocline depth anomaly, respectively, and the bar and prime denote the climatological mean and the variables in the linearized model, respectively.
3. The wind stress formation in the Zebiak-Cane model:

$\tau=\rho_{0} C_{D}|(\bar{V}+V)|(\bar{V}+V)-\rho_{0} C_{D}|\bar{V}| \bar{V}$,

where $\bar{V}=(\bar{u}, \bar{v}), V=(u, v)$.

The wind stress in the L-WSA model is $\tau^{\prime}=\left(\tau_{x}^{\prime}, \tau_{y}^{\prime}\right)$

$\left\{\begin{array}{l}\tau_{x}^{\prime}=\rho_{0} C_{D} \frac{2 \bar{u}^{2}+\bar{v}^{2}}{\sqrt{\bar{u}^{2}+\bar{v}^{2}}} u^{\prime}+\rho_{0} C_{D} \frac{\bar{u}+\bar{v}}{\sqrt{\bar{u}^{2}+\bar{v}^{2}}} v^{\prime}, \\ \tau_{y}^{\prime}=\rho_{0} C_{D} \frac{\bar{u}+\bar{v}}{\sqrt{\bar{u}^{2}+\bar{v}^{2}}} u^{\prime}+\rho_{0} C_{D} \frac{\bar{u}^{2}+2 \bar{v}^{2}}{\sqrt{\bar{u}^{2}+\bar{v}^{2}}} v^{\prime} .\end{array}\right.$

The tendency of the effect of nonlinearities associated with wind stress anomalies (WSA) on El Niño is indicated by the signs of $\tau-\tau^{\prime}$.

\section{References}

An S-I, Wang B (2001) Mechanisms of locking the El Niño and La Niña mature phases to boreal winter. J Climate 14:2164-2176

An S-I, Jin FF (2004) Nonlinearity and asymmetry of ENSO. J. Climate 17:2399-2412

Battisti DS, Hirst AC (1989) Interannual variability in the tropical atmosphere/ocean system: influences of the basic state, ocean geometry and nonlinearity. J Atmos Sci 46:1687-1712

Birgin EG, Martínez JM, Raydan M (2000) Nonmonotone spectral projected gradient methods on convex sets. Society for industrial and applied mathematics. J Optimaizat 10:1196-1211

Blumenthal MB (1991) Predictability of a coupled atmosphere-ocean model. J Climate 4:766-784

Chen D, Cane MA, Kaplan A, Zebiak SE, Huang DJ (2004) Predictability of El Niño over the past 148 years. Nature 428(6984):733-736

Cheng YJ, Tang YM, Zhou XB, Jackson P, Chen D (2009) Further analysis of singular vector and ENSO predictability in the Lamont model-Part I: singular vector and the control factors. Clim Dyn. doi:10.1007/s00382-009-0595-7

Duan WS, Mu M (2006) Investigating decadal variability of El NiñoSouthern Oscillation asymmetry by conditional nonlinear optimal perturbation. J Geophys Res 111:C07015. doi:10.1029/2005 JC003458

Duan WS, Mu M (2009) Conditional nonlinear optimal perturbation: applications to stability, sensitivity, and predictability. Sci China (D) 52:884-906

Duan WS, Mu M, Wang B (2004) Conditional nonlinear optimal perturbations as the optimal precursors for El Niño-Southern Oscillation events. J Geophys Res 109:D23105. doi:10.1029/ 2004JD004756

Duan WS, Xu H, Mu M (2008) Decisive role of nonlinear temperature advection in El Niño and La Niña amplitude asymmetry. J Geophys Res 113:C01014. doi:10.1029/2006JC003974

Duan WS, Xue F, Mu M (2009) Investigating a nonlinear characteristic of El Niño events by conditional nonlinear optimal perturbation. Atmos Res 94:10-18

Jin FF (1997a) An equatorial ocean recharge paradigm for ENSO. Part I: conceptual model. J Atmos Sci 54:811-829

Jin FF (1997b) An equatorial ocean recharge paradigm for ENSO. Part II: a stripped-down coupled model. J Atmos Sci 54:830-847 
Jin FF, An S-I, Timmermann A, Zhao JX (2003) Strong El Niño events and nonlinear dynamical heating. Geophys Res Lett 30:1120. doi:10.1029/2002GL016356

Kirtman BP, Shukla J, Balmaseda M, Graham N, Penland C, Xue Y, Zebiak S (2002) Current status of ENSO forecast skill: a report to the climate variability and predictability (CLIVAR) numerical experimentation group (NEG), CLIVAR working group on seasonal to interannual prediction, Clim. Variability and Predictability, Southampton Oceanogr. Cent., Southampton, UK

Kleeman R (1993) On the dependence of hindcast skill on ocean thermodynamics in a coupled ocean-atmosphere model. J Clim 6:2012-2033

Liu DC, Nocedal J (1989) On the limited memory method for large scale optimization. Math Program B 45(3):503-528

Lorenz EN (1965) A study of the predictability of a 28-variable atmospheric model. Tellus 17:321-333

Moore AM, Kleeman R (1996) The dynamics of error growth and predictability in a coupled model of ENSO. Quart J Roy Met Soc 122:1405-1446

Mu M, Duan WS (2003) A new approach to studying ENSO predictability: conditional nonlinear optimal perturbation. Chinese Sci Bull 48:1045-1047

Mu M, Zhang ZY (2006) Conditonal nonlinear optimal perturbation of a barptrophic model. J Atmos Sci 63:1587-1604

Mu M, Duan WS, Wang B (2003) Conditional nonlinear optimal perturbation and its applications. Nonlinear Process Geophys 10:493-501

Mu M, Duan WS, Wang B (2007a) Season-dependent dynamics of nonlinear optimal error growth and El Niño-Southern Oscillation predictability in a theoretical model. J Geophys Res 112: D10113. doi:10.1029/2005JD006981

Mu M, Xu H, Duan WS (2007b) A kind of initial errors related to "spring predictability barrier" for El Niño events in Zebiak-Cane model. Geophys Res Lett 34:L03709. doi:10.1029/2006GL27412

Mu M, Zhou FF, Wang HL (2009) A method for identifying the sensitive areas in targeted observations for tropical cyclone prediction: conditional nonlinear optimal perturbation. Mon Wea Rev 137(5):1623-1639

Munnich M, Cane MA, Zebiak SE (1991) A study of self-exicited oscillations of the tropical ocean-atmosphere system. Part II: nonlinear cases. J Atmos Sci 48:1238-1248

Neelin JD (1991) The slow sea surface temperature mode and the fast-wave limit: analytic theory for tropical interannual oscillations and experiments in a hybird coupled model. J Atmos Sci 48:584-606
Peland C, Sardeshmukh P (1995) The optimal growth of tropical sea surface temperature anomalies, J. Climate 8:1999-2004

Philander SG (1990) El Niño, La Nina, and the Southern Oscillation. Academic Press, London

Picaut J, Masia F, du Penhoat Y (1997) An advective-reflective conceptual model for the oscillatory nature of the ENSO. Science 277:663-666

Powell MJD (1982) VMCWD: a FORTRAN subroutine for constrained optimization. DAMTP report 1982/NA4. University of Cambridge, England

Rodgers KB, Friederichs P, Latif M (2004) Tropical Pacific decadal variability and its relation to decadal modulations of ENSO, J. Climate 17:3761-3774

Rosati A, Miyakoda K, Gudgel R (1997) The impact of ocean initial conditions on ENSO forecasting with a coupled model. Mon Wea Rev 125:754-772

Suarez MJ, Schopf PS (1988) A delayed action oscillator for ENSO. J Atmos Sci 45:3283-3287

Tang Y, Deng Z, Zhou X, Cheng Y, Chen D (2008) Interdecadal variation of ENSO predictability in multiple models. J Climate 21:4811-4833

Timmermann A, Jin FF (2002) A nonlinear mechanism for decadal El Niño amplitude changes. Geophys Res Lett 29:1003. doi: 10.1029/2001GL013369

Wang C (2001) A unified oscillator model for the El Niño-Southern Oscillation. J Climate 24:98-115

Wang B, Fang Z (1996) Chaotic oscillations of tropical climate: a dynamic system theory for ENSO. J Atmos Sci 53:2786-2802

Wang C, Picaut J (2004) Understanding ENSO physics-a review. Earth climate: the Ocean-Atmosphere interaction. Geophys Monogr Am Geophys Union 147:21-48

Wang CZ, Weisberg RH, Virmani JI (1999) Western Pacific interannual variability associated with the El Niño-Southern Oscillation. J Geophys Res 104:5131-5149

Xue Y, Cane MA, Zebiak SE, Blumenthal MB (1994) On the prediction of ENSO, a study with a low-order Markov model. Tellus 46A:512-528

Xue Y, Cane MA, Zebaik SE (1997) Predictability of a coupled model of ENSO using singular vector analysis. Part I: optimal growth in seasonal background and ENSO cycles. Mon Weather Rev 125:2043-2056

Zebiak SE (1986) Atmospheric convergence feedback in a simple model for El Niño. Mon Wea Rev 114:1263-1271

Zebiak SE, Cane MA (1987) A model El Niño -Southern Oscillation. Mon Wea Rev 115:2262-2278 